\title{
Negative Affect and Counterproductive Work Behavior: Roles of Arousal Level*
}

\author{
Yongjun Choi** \\ Ohsoo Park Pa* $^{*}$
}

Negative affect is examined for its influences on counterproductive work behavior (CWB) aimed at individuals (CWBI) or organizations (CWBO). The circumplex model of affect is applied to a sample of 264 employees in South Korea. Results support the predictions that high arousal negative affect is positively associated with CWBI and low arousal negative affect is positively associated with CWBO. Limitations and implications are discussed.

Keywords: counterproductive work behavior, affect, circumplex model of affect

\section{Introduction}

Factors that lead employees to behave in ways that contradict organizational goals have been well documented (for a review, see Berry, Ones, and Sackett, 2007; Dalal, 2005; Lau, Au, and Ho, 2003; Sackett and DeVore, 2001). Counterproductive behavior (CWB) refers to "behavior that is intended to have a detrimental effect on organizations and their members" (Fox, Spector, and Miles, 2001: 292). CWB can be motivated by situational factors such as conflict (Bruk-Lee and Spector, 2006; Fox, Spector, and Miles, 2001), organizational constraints (Fox et al., 2001), individual differences such as narcissism (Penney and Spector, 2002), and big five personality

\footnotetext{
*This Study was supported by the Institute of Management Research at Seoul National University.

**Professor, College of Business, Wright State University

***Ph.D. College of Business Administration, Seoul National University
} 
characteristics (Salgado, 2002). Most CWB research has emphasized that overall negative affect or discrete negative emotions are mediators in these relationships. For example, negative affect has been shown to mediate the relationship between conflict and CWB (Bruk-Lee and Spector, 2006; Fox et al., 2001); and anger has been shown to mediate the relationship between narcissism and CWB (Penney and Spector, 2002). The emphasis on overall negative affect and discrete emotions in explaining CWB supports the concept that CWB reflects "a need to vent, release, or express one's feelings of outrage, anger, or frustration" (Robinson and Bennett, 1997: 18).

However, interestingly, most previous research has merely demonstrated that negative emotions have overall relationships with CWB. Although researchers showed that negative affect/emotions predict CWB, they failed to examine whether and how they may cause CWB. This current research adopts the circumplex model of affect (Russell, 1980) to scrutinize affect for its roles in generating positive versus negative hedonic tones and high versus low arousal levels.

Before affect in the workplace is discussed, the differences between trait affect and state affect must be clarified. State affect identifies transitory, fluctuating moods in individuals; trait affect identifies stable individual negative affect levels (Cohen, Doyle, Skoner, Fireman, Gwaltney, and Newsom, 1995). For the purposes of this study, the focus is on employees' affect states at work, so affect in this study refers to state affect rather than trait affect. Specifically, the objective is to investigate negative affect arousal levels as predictors of CWB targets; that is whether employees will direct CWB toward individuals or organizations.

Most previous CWB literature relied heavily on western samples. Although CWB is a universal phenomenon, it may be manifested differently in various cultures. For instance, Lee (2001) used Bennett and Robinson's (2000) measure of CWB and revealed that Korean culture differs substantially from Australian and Canadian cultures in terms of Hofstede's five dimensions of culture (Hofstede, 1994; Hofstede and Bond, 1988). Thus, grounded in Lee (2001), the current study aims to investigate CWB in South Korea and to develop CWB measures appropriate for Korean culture. 
In summary, the primary purpose of this study is to examine negative affect as it influences high or low arousal levels that will in turn determine specific CWB targets. Second, the focus is on CWB in South Korea. Although researchers have studied organizational citizenship behavior (OCB) or other work behaviors in nonWestern countries, they have generally assumed that CWB is universal across nations and cultures and have rarely researched cross-cultural differences regarding CWB in Asian countries (Lee, 2001). Thus, it is meaningful to examine CWB beyond the Western context while also contributing to the literature dealing with both emotions and CWB.

\section{Hypotheses Development}

Numerous empirical findings have indicated that negative affect is related to negative work behaviors such as absenteeism and theft (Chen and Spector, 1992; George, 1989). CWB goes beyond specific counterproductive behaviors to capture a broader range of deviant behaviors. A meta-analysis (Berry et al., 2007) demonstrated that CWB can be directed toward individuals (CWBI) and organizations (CWBO).

The source of conflict may determine whether individuals aim their CWB at specific individual or organizational targets. For instance, conflict with coworkers other than supervisors has been shown to predict CWBI, while conflict with either coworkers or supervisors predicts CWBO (Bruk-Lee and Spector, 2006). In addition, both positive and negative job affect is more likely than job cognition to predict CWB. That is, job affect better predicted CWBI and job cognition better predicted CWBO $(\rho=.91)$ when only one overall construct of CWB was considered because CWBI and CWBO are highly correlated (Lee and Allen, 2002). The current study, based on the circumplex model of affect (Russell, 1980), incorporates both positive and negative valence and high and low arousal affect levels to investigate their effects on CWB target specificity. 
Traditionally, negative and positive affect have been treated as being independent and separate, as in the PANAS (Positive Affect and Negative Affect Schedule; Watson and Clark, 1994). In contrast, the circumplex model of affect (Russell, 1980) treats negative and positive affect as systematically interrelated. Consequently, PANAS produces two independent scores for positive and negative affect, but the circumplex model of affect captures positive or negative hedonic tones and high or low arousal levels. For instance, high arousal negative affect (HANA) includes emotions such as anger or anxiety; low arousal negative affect (LANA) includes emotions such as boredom or depression. Previous research showed that applying a circumplex model of affect enhances the external validity of predictive and explanatory power in affect research (Wirtz, 1994; Wirtz and Bateson, 1999), and allows affect and cognition to be distinguished (Mattila and Wirtz, 2000).

Both hedonic tones and arousal affect levels play significant roles in determining behaviors. Recently, similar to a circumplex model of affect, affect was shown to have circular effects on social behavior; for example, individuals who experience high arousal and low valence will "act irritated" and "seem detached," while individuals who experience low arousal and high valence will "blame others," or "speak negatively" about others (Carney and Colvin, 2010). Thus, given the same valence of affect, the more individuals are aroused the more they tend to display observable behaviors that affect others. The response-facilitation model also argues that arousal causes individuals to display their dominant affect reactions (Pastor, Mayo, and Shamir, 2007).

CWBI is more easily observed than is CWBO, and thus individuals can choose CWBI as a more direct way to express their uncomfortable affect states. For instance, team members will notice when one disgruntled team member publicly embarrasses another member; everyone will know that the perpetrator dislikes the target. In contrast, CWBO is a less-observable, less-direct way of displaying negative affect. For example, only perpetrators will know that they are intentionally working slowly; others may barely notice. Hence, employees with HANA will be more likely to display CWBI. On the other hand, those with LANA will be more likely to 
display CWBO.

Hypothesis 1a \& 1b. HANA and LANA are positively related to CWBI (1a) and CWBO (1b).

Hypothesis 2a. HANA is more strongly related to CWBI than to CWBO.

Hypothesis 2b. LANA is more strongly related to CWBO than to CWBI.

\section{Methods}

\section{Participants}

Two survey packets were distributed to 410 employees in 22 organizations, including financial, service, and manufacturing industries, located in South Korea. Of the 357 employees who completed the surveys (response rate $=87.07 \%$ ), 264 participants provided two matched responses (final response rate $=64.39 \%$ ). Of the participants, $54.92 \%$ were men, with an average age of 32.28 years $(\mathrm{SD}=7.57)$. Organization tenure averaged 5.56 years $(\mathrm{SD}=6.79)$.

\section{Procedures}

Anonymous and voluntary surveys were administered twice, one week apart. Basic demographic variables and negative affect were answered at Time 1, and CWB questions were answered one week later, at Time 2. To match the two sets of responses, respondents used the same number, letter, or sign of their choice in both survey packets.

\section{Measures}

All items were measured using a seven-point Likert-type scale except for CWB items, which were measured using a nine-point Likert scale. 


\section{1) Control Variables}

Demographic variables such as gender, age, education level, position, and organizational tenure were controlled.

\section{2) Negative Affect}

Negative affect was measured using ten items from the short version of JAWS (Job-related Affective Well-being Scale; Van Katwyk, Fox, Spector, and Kelloway, 2000). JAWS enabled measurement of howfre quently participants experienced certain emotions related to their jobs and also allowed measurement of pure affect rather than beliefs or attitudes as is typical in job satisfaction studies (Van Katwyk et al., 2000). Of the ten items, one for low arousal negative affect was dropped because it was cross-loaded and had low communality. Consequently, five items were used to measure high arousal negative affect $(\alpha=.891)$ and four items were used to measure low arousal negative affect $(\alpha=.845)$. For example, "My job made me feel furious" for HANA, and "My job made me feel gloomy" for LANA. The rating scale ranged from 1 (never) through 7 (extremely often).

\section{3) Counterproductive Work Behavior}

Using Bennett and Robinson's (2000) measures based on Hofstede's five dimensions of culture (Hofstede, 1994; Hofstede and Bond, 1988), Lee (2001) showed that Korean culture is substantially different from Australian and Canadian culture. However, Berry et al. (2007) confirmed the two-factor structure (CWBI and CWBO) across the three cultures. Hence, ten CWB items for Korean culture were created for the current study. First, 19 common items were derived based on three instruments (Aquino, Lewis, and Bradfield, 1999; Bennett and Robinson, 2000; Kelloway, Loughlin, Barling, and Nault, 2002), after dropping irrelevant or unacceptable items in the South Korea context (e.g., "Made an ethnic, religious, or racial remark at work"). Next, eight graduate students who are majoring in organizational behavior and who have job experiences added six items through the item generation process. Eight other graduate students reviewed and revised the 
items to enhance the face validity of the final 25 items.

Finally, five items were derived for CWBI and seven for CWBO. Fifty-nine employed individuals took part in a pilot test for the twelve items using web-based survey software and provided 52 usable answers. The first principal component analysis in conjunction with varimax rotation produced a two-factor solution (seven items for CWBI and five for CWBO). However, one item for CWBI and one item for CWBO were dropped because their item-total correlations were below 0.3 (Nunnally and Bernstein, 1994). The second principal component analysis also produced a two-factor solution, including six items $(\alpha=.902)$ for CWBI and four items for CWBO $(\alpha=.657)$ with eigenvalues of 4.917 and 1.401, respectively, which explained $49.167 \%$ and $14.014 \%$ of the variance. Finally, a management scholar reviewed the items and recommended that one item for CWBI should be deleted, and one item for CWBO should be added, leaving ten items (five for each) to measure CWB (see Appendix for the final items). However, one item, "Worked at my discretion ignoring the implicit or explicit rules of my team," was dropped because it was cross-loaded and had low communality. Consequently, five items were used to measure CWBI $(\alpha=.843) 5$ and four items were used to measure CWBO $(\alpha=.786)$. For example, "Acted rudely toward someone on my team" to assess CWBI, and "Intentionally work slowly compared to my abilities" to assess CWBO. The rating scale ranged from 1 (never) through 9 (extremely often).

\section{Results}

Descriptive statistics are presented in Table 1.

Hypotheses $1 \mathrm{a}$ and $1 \mathrm{~b}$ posit that negative affect (i.e., HANA and LANA) is positively related to CWBI and CWBO. Table 2 shows that HANA but not LANA $(\beta$ $=.041$, n.s. $)$ is positively associated with CWBI $(\beta=.292, \mathrm{p}<.001)$; LANA $(\beta=$ $.233, \mathrm{p}<.01)$ but not HANA $(\beta=.128$, n.s. $)$ is positively related to CWBI. Hence, Hypotheses $1 \mathrm{a}$ and $1 \mathrm{~b}$ are partially supported. Consequently, with respect to 
〈Table 1〉 Means, Standard Deviations, and Correlations

\begin{tabular}{r|c|r|r|c|c|c|c|c|c|c|c|c}
\hline & Variable & Mean & \multicolumn{1}{|c|}{ SD } & GEN & AGE & EDU & TEN & PSN & HANA & LANA & CWBI & CWBO \\
\hline 1 & GEN & 1.45 & .498 & 1 & & & & & & & & \\
\hline 2 & AGE & 32.28 & 7.565 & $-.337^{* *}$ & 1 & & & & & & & \\
\hline 3 & EDU & 3.68 & .877 & -.1 & $-.139^{*}$ & 1 & & & & & & \\
\hline 4 & TEN & 66.69 & 81.517 & $-.177^{* *}$ & $.714^{* *}$ & $-.127^{*}$ & 1 & & & & & \\
\hline 5 & PSN & 1.97 & 1.257 & $-.274^{* *}$ & $.671^{* *}$ & $.168^{* *}$ & $.637^{* *}$ & 1 & & & & \\
\hline 6 & HANA & 3.07 & 1.226 & $.125^{*}$ & -0.1 & -0.02 & -0.1 & $-.124 *$ & $(.891)$ & & & \\
\hline 7 & LANA & 2.80 & 1.230 & $.179^{* *}$ & $-.122^{*}$ & -0.07 & -0.11 & $-.143^{*}$ & $.683 * *$ & $(.845)$ & & \\
\hline 8 & CWBI & 2.31 & 1.098 & -0.09 & -0 & 0.054 & 0 & 0.014 & $.296 * *$ & $.211 * *$ & $(.843)$ & \\
\hline 9 & CWBO & 2.07 & 1.040 & -0.09 & $-.156^{*}$ & 0.089 & $-.137^{*}$ & -0.11 & $.277 * *$ & $.299 * *$ & $.452^{* *}$ & $(.786)$ \\
\hline
\end{tabular}

Note: $\mathrm{N}=264$. The numbers on the diagonal are the coefficient alphas; GEN = gender $(1=$ male, $2=$ female $)$; EDU: educational level ( 1 = below high school diploma, $2=$ high school diploma, $3=$ associate degree, $4=$ bachelor's degree, 4 = above master's degree); TEN: tenure; PSN: position; HANA: high arousal negative affect; LANA: low arousal negative affect; CWBI: counterproductive work behavior directed toward individuals; CWBO: counterproductive work directed toward the organization; ${ }^{*} \mathrm{p}<.05 ;{ }^{* *} \mathrm{p}<.01$ (two-tailed).

〈Table 2〉 Regression Results

\begin{tabular}{l|c|c|c|c}
\hline \multirow{2}{*}{\multicolumn{1}{c|}{ Variable }} & \multicolumn{2}{|c|}{ CWBI } & \multicolumn{2}{c}{ CWBO } \\
\cline { 2 - 5 } & Model 1 & Model 2 & Model 3 & Model 4 \\
\hline Step 1: Control Variables & & & & \\
Gender & -.094 & $-.120 \dagger$ & $-.158^{*}$ & $-.196^{* *}$ \\
Age & -.038 & -.014 & -.157 & -.131 \\
Education & .036 & .037 & .045 & .058 \\
Tenure & .009 & .011 & -.031 & -.022 \\
Position & .007 & .026 & -.028 & -.014 \\
Step 2: Main Effects & & & & \\
High Arousal Negative Affect & & $.292^{* * *}$ & & .128 \\
Low Arousal Negative Affect & & .041 & & $.233^{* *}$ \\
\hline Overall F & .503 & 4.412 & 2.554 & 6.523 \\
$\mathrm{R}^{2}$ & .010 & .110 & .048 & .155 \\
F change & .503 & $14.054^{* * *}$ & 2.554 & $15.697^{* * *}$ \\
$\mathrm{R}^{2}$ change & .010 & $.100^{* * *}$ & .048 & $.107^{* * *}$ \\
\hline
\end{tabular}

Note: $\mathrm{N}=264 . \dagger \mathrm{p}<.10 ;{ }^{*} \mathrm{p}<.05 ;{ }^{* *} \mathrm{p}<.01 ;{ }^{* * *} \mathrm{p}<.001$ (two-tailed). 
Hypotheses $2 \mathrm{a}$ and $2 \mathrm{~b}$, as expected, HANA is more strongly and significantly related to CWBI while LANA is more strongly and significantly related to CWBO. Thus, Hypotheses $2 \mathrm{a}$ and $2 \mathrm{~b}$ are supported.

\section{Discussion}

This study provides intriguing results regarding negative affect according to arousal levels for predicting counterproductive work behaviors (CWB). Arousal levels cause individuals to display their dominant responses to stimuli (Pastor, Mayo, and Shamir, 2007): "when emotional information cues reach sufficient thresholds of arousal, collateral negative behavior may be manifested in turn" (Yang and Mossholder, 2004: 592). Accordingly, the study shows that high arousal negative affect (HANA) is significantly and positively related to CWB aimed at individuals (CWBI), while low arousal negative affect (LANA) is significantly and positively associated with CWB aimed at organizations (CWBO). Behaviors directed toward individuals are more directly observable expressions than are behaviors directed toward organizations. Hence, employees who have HANA are more inclined to show CWBI rather than CWBO, and those with LANA are more likely to show the less-direct CWBO.

\section{Limitations and Implications}

This study has some limitations. First, the preliminary level measurement for CWB was grounded on extant instruments and validated through a pilot test, but some doubts still arise regarding the measurement's validity. Therefore, future research should further validate the scale in South Korea. Second, the current study may suffer from common method biases. Despite the one-week time lag between the two surveys, all variables were measured by a single source. In addition, a 
one-week interval might be insufficient to control the effects of common method biases. Last, since CWB reflects cultural characteristics across countries, the research question should be tested in Western countries to generalize the results.

Despite the limitations, this study enriches understanding about the relationships between negative affect and CWB. Especially regarding arousal levels, employees with HANA are much more inclined to target individuals, while employees with LANA are much more likely to target organizations. Thus, behavioral reactions differ based on the arousal level of affect even if employees have similar hedonic tones. Therefore, by using the circumplex model of affect, both hedonic tone and the arousal level of affect are worth considering for a closer examination of how affect influences employees' attitudes and behaviors at work. As previously demonstrated (e.g., Bruk-Lee and Spector, 2006; Lee and Allen, 2002), it is important to know which antecedents determine target specificity. Thus, the findings contribute to CWB literature. On a practical level, the findings imply that organizations should closely monitor employees' affective states to assure that their work behavior follows desirable pathways. Caution in managing employees' affective states is especially advisable in emotional labor occupations such as sales.

Second, CWB was examined in an Asian country, specifically South Korea. Since CWB includes cultural differences (Lee, 2001), it is critical to investigate CWB outside the usual western contexts. Future researchers should use the CWB measurement created to fit the South Korean workplace and test it in Western countries to determine whether diverse cultures will show different CWB antecedents and consequences.

\section{References}

Aquino, K., Lewis, M. U., and Bradfield, M. (1999), "Justice Constructs, Negative Affectivity, and Employee Deviance: A Proposed Model and Empirical Test,” Journal of Organizational Behavior, 20, 1073-1091. 
Bennett, R. J. and Robinson, S. L. (2000), "Development of Measure of Workplace Deviance," Journal of Applied Psychology, 85, 349-360.

Bennett, R. J. and Robinson, S. L. (2003), "The Past, Present, and Future of Workplace Deviance Research," in J. Greenberg (Ed.), Organizational Behavior: The State of the Science (pp. 247-281), Mahwah, NJ: Lawrence Erlbaum.

Berry, C. M., Ones, D. S., and Sackett, P. R. (2007), "Interpersonal Deviance, Organizational Deviance and Their Common Correlates: A Review and Meta-analysis," Journal of Applied Psychology, 92, 410-424.

Bruk-Lee, V. and Spector, P. E. (2006), "The Social Stressors-counterproductive Behaviors Link: Are Conflicts with Supervisors Coworkers the same?" Journal of Occupational Health Psychology, 11, 145-156.

Carney, D. R. and Colvin, R. (2010), "The Circumplex Structure of Affective Social Behavior," Social Psychological and Personality Science, 1, 73-80.

Chen, P. and Spector, P. (1992), "Relationships of Work Stressors with Aggression, Withdrawal, Theft and Substance Use: An Eexploratory Study," Journal of Occupational and Organizational Psychology, 65, 177-184.

Cohen, S., Doyle, W. J., Skoner, D. P., Fireman, P., Gwaltney, J. M. Jr., and Newsom, J. T. (1995), "State and Trait Affect as Predictors of Objective and Subjective Symptoms of Rrespiratory Viral Infections," Journal of Personality and Social Psychology, 68, 159-169.

Dalal, R. S. (2005), "A Meta-analysis of the Rrelationship between Organizational Citizenship Behavior and Counterproductive Work Behavior," Journal of Applied Psychology, 90, 1241-1255.

Fox, S., Spector, P. E., and Miles, D. (2001), "Counterproductive Work Behavior (CWB) in Rresponse to Job Stressors and Organizational Justice: Some Mediator and Moderator Tests for Autonomy and Emotions," Journal of Vocational Behavior, 59, $291-309$.

George, J. M. (1989), "Mood and Aabsence," Journal of Applied Psychology, 74, 317324.

Hofstede, G. (1994), "Cultures and Organisations: Intercultural Cooperation and Its Importance for Survival," Software of the Mind, Cambridge, UK: McGraw-Hill International.

Hofstede, G. and Bond, M. (1988), "The Confucius Connection: From Cultural Roots to Economic Growth,” Organizational Dynamics, 16, 4-21. 
Kelloway, E. K., Loughlin, C., Barling, J., and Nault, A. (2002), "Self-reported CounterProductive Behaviors and Organizational Citizenship Behaviors: Separate but Related Constructs," International Journal of Selection and Assessment, 10, 143-151.

Lau, V. C. S., Au, W. T., and Ho, J. M. C. (2003), "A Qualitative and Quantitative Review of Antecedents of Counterproductive Behavior in Organizations," Journal of Business and Psychology, 18, 73-99.

Lee, Y. H. (2001), "Do Employees from Different Cultures Interpret Workplace Deviance Measures in an Equivalent Way?" Unpublished master's thesis, The University of Western Australia, Perth, Australia.

Lee, K. and Allen, N. J. (2002), "Organizational Citizenship Behavior and Workplace Deviance: The Rrole of Affect and Cognitions," Journal of Applied Psychology, 87, 131-142.

Mattila, A. and Wirtz, J. (2000), "The Impact of Pre-consumption Affect on Service Satisfaction," Psychology \& Marketing, 17, 587-605.

Nunnally, J. C. and Bernstein, I. H. (1994), Psychometric Theory (3rd ed.), New York: McGraw-Hill.

Pastor, J. C., Mayo, M., and Shamir, B. (2007), "Adding Fuel to Fire: The Impact of Followers' Arousal on Ratings of Charisma," Journal of Applied Psychology, 92, $1584-1596$.

Penney, L. M. and Spector, P. E. (2002), "Narcissism and Counterproductive Work Behavior: Do Bigger Egos Mean Bigger Problems?" International Journal of Selection and Assessment, 10, 126-134.

Podsakoff, P. M., MacKenzie, S. B., Lee, J-Y., and Podsakoff, N. P. (2003), "Common Method Biases in Behavioral Research: A Critical Review of the Literature and Recommended Remedies," Journal of Applied Psychology, 88, 879-903.

Robinson, S. L. and Bennett, R. J. (1995), "A Typology of Deviant Workplace Behaviors: A Multidimensional Scaling Study," Academy of Management Journal, 38, 555-572. Robinson, S. L. and Bennett, R. J. (1997), "Workplace Deviance: Its Definition, Its Manifestations, and Its Causes," in R. J. Lewicki, B. H. Sheppard, and R. J. Bies (Eds.), Research on Negotiation in Organizations, vol. 7, pp. 3-27. Greenwich, CT: JAI Press.

Russell, J. (1980), “A Circumplex Model of Affect," Journal of Personality and Social Psychology, 39, 1161-1178.

Sackett, P. R. and DeVore, C. J. (2001), “Counterproductive Behaviors at Work," in N. 
Anderson, D. S. Ones, H. K. Sinangil, and C. Visweswaran (Eds.), Handbook of Industrial, Work, \& Organizational Psychology, vol. 1, pp. 145-166. Thousand Oaks, CA: Sage.

Salgado, J. F. (2002), “The Big Five Personality Dimensions and Counterproductive Behaviors," International Journal of Selection and Assessment, 10, 117-125.

Spector, P. E. and Fox, S. (2002), "An Emotion-centered Model of Voluntary Work

Behavior: Some Parallels between Counterproductive Work Behavior (CWB) and Organizational Citizenship Behavior (OCB)," Human Resources Management Review, 12, 269-292.

Spector, P. E. and Jex, S. M. (1998), "Development of Four Self-report Measures of Job Stressors and Strain: Interpersonal Conflict at Work Scale, Organizational Constraint Scale, Quantitative Workload Inventory, and Physical Symptoms Inventory," Journal of Occupational Health Psychology, 3, 356-367.

Stone, A. A. (1981), "The Association between Perceptions of Daily Experience and Self-and Spouse-rated Mood," Journal of Research in Personality, 15, 510-522.

Van Katwyk, P. T., Fox, S., Spector, P. E., and Kelloway, E. K. (2000), "Using the Job-related Affective Well-being Scale (JAWS) to Investigate Affective Response to Work Stressors," Journal of Occupational Health Psychology, 5, 219-230.

Warr, P., Barter, J., and Brownbridge, G. (1983), "On the Interdependence of Positive and Negative Affect," Journal of Personality and Social Psychology, 44, 644-651. Watson, D. and Clark, L. A. (1994), "The PANAS-X: Manual for the Positive and Negative Affect Schedule-expanded Form," Unpublished manuscript, University of Iowa, Iowa City.

Wirtz, J. (1994), "The Affect Literature in Psychology: A Review for Consumer Behaviorists," Asian Journal of Marketing, 3, 59-62.

Wirtz, J. and Bateson, J. E. (1999), "Consumer Satisfaction with Services: Integrating the Environmental Perspective in Services Marketing into the Traditional Disconfirmation Paradigm," Journal of Business Research, 44, 55-66.

Yang, J. and Mossholder, K. W. (2004), "Decoupling Task and Relationship Conflict: The Role of Intragroup Emotional Processing," Journal of Organizational Behavior, 25, $589-605$. 
Appendix

Counterproductive Work Behavior Scale Items

Measures

CWBI (Counterproductive Work Behavior Directed Toward Individuals)

Acted rudely toward someone on my team

Gossiped about someone on my team

Said something harmful to someone on my team

Publicly embarrassed someone on my team

Cursed at someone at work

CWBO (Counterproductive Work Behavior Directed Toward the Organization)

Dragged out work in order to get overtime pay

Covered up (or reported to supervisors by minimizing) my mistakes related to a task

Worked at my discretion ignoring the implicit or explicit rules of my team

Intentionally worked negligently

Intentionally worked slowly compared to my abilities 